\title{
Monitoring thermal status of ecosystems with MODIS land-surface temperature and vegetation index products
}

\author{
Zhengming Wan \\ Institute for Computational Earth System Science \\ University of California, Santa Barbara, CA 93106
}

\begin{abstract}
The global land-surface temperature (LST) and normalized difference vegetation index (NDVI) products retrieved from Moderate Resolution Imaging Spectroradiometer (MODIS) data in 2001 were used in this study. The yearly peak values of NDVI data at $5 \mathrm{~km}$ grids were used to define six NDVI peak zones from -0.2 to 1 in steps of 0.2 , and the monthly NDVI values at each grid were sorted in decreasing order, resulting in 12 layers of NDVI images for each of the NDVI peak zones. The mean and standard deviation of daytime LSTs and day-night LST differences at the grids corresponding to the first layer of NDVI images characterize the thermal status of terrestrial ecosystems in the NDVI peak zones. For the ecosystems in the 0.8-1 NDVI peak zone, daytime LSTs distribute from $0-35{ }^{\circ} \mathrm{C}$ and day-night LST differences distribute from -2 to $22^{\circ} \mathrm{C}$. The daytime LSTs and day-night LST differences corresponding to the remaining layers of NDVI images show that the growth of vegetation is limited at low and high LSTs. LSTs and NDVI may be used to monitor photosynthetic activity and drought, as shown in their applications to a flood-irrigated grassland in California and an unirrigated grassland in Nevada.
\end{abstract}

Keywords: MODIS, land-surface temperature, NDVI, ecosystem, photosynthetic activity, drought

\section{INTRODUCTION}

As a part of the NASA-centered international Earth Observing System (EOS), two MODIS instruments ${ }^{1}$ have been launched to provide information for global studies of atmosphere, land, and ocean processes. The first one was launched 18 December 1999 on the morning platform called Terra, and the second one was launched 4 May 2002 on the afternoon platform called Aqua. The strengths of MODIS include its global coverage, high radiometric resolution and dynamic ranges, and accurate calibration in visible, near-infrared and thermal infrared bands. The Terra MODIS data have been used to generate science data products for more than two years and these science data products are available to the public free of charge. A consistent reprocessing has been made for Terra MODIS data since November 1999 to generate science data products (in version 3) in either provisional quality or validated quality. Science data products based on Aqua MODIS data will also be available after the testing and evaluation stage.

NDVI and LST are two of the MODIS land product suite. ${ }^{2}$ The MODIS VI products have been designed for seasonal and interannual monitoring of the Earth's vegetation. The NDVI product maintains continuity with the NDVI data record from the Advanced Very High Resolution Radiometers (AVHRR). ${ }^{3,4}$ Vegetation indices have been use to conduct land cover classifications, ${ }^{5}$ and derive biophysical properties of the vegetation such as fractional vegetation cover, biomass, leaf area index, faction of absorbed photosynthetic active radiation and phenology. $6,7,8$

LST is one of the key parameters in the physics of land-surface processes on regional and global scales, combining the results of all surface-atmosphere interactions and energy fluxes between the atmosphere and the ground. ${ }^{9}, 10$ The remotely sensed LST has been used in land cover and land-cover change analysis, ${ }^{11}, 12$ and in the production of the MODIS land cover product. It has also been used in monitoring drought and estimating surface soil moisture, ${ }^{13,14}$ evaluating water requirements of wheat, ${ }^{15}$ and determining frosts in orange groves. ${ }^{16}$

The level-2 MODIS LST product (MOD11_L2) is retrieved with the generalized split-window LST algorithm ${ }^{17}$ from the calibrated radiance data of bands 31 and 32 data in the MODIS Level-1B $1 \mathrm{~km}$ resolution (MOD021KM) product. Other inputs to this algorithm include MODIS geolocation product (MOD03), cloudmask product (MOD35), and atmospheric temperature and water vapor profile product (MOD07). The emissivities in bands 31 and 32 are estimated from land cover types $^{18}$ in the MODIS land-cover product (MOD12Q) and snow cover product (MOD10) through look-up tables established by TIR BRDF (bidirectional reflectance distribution function) and emissivity modeling. ${ }^{19}$ The errors and uncertainties in the classification-based emissivities may be large in semi-arid and arid regions because of the large 
temporal and spatial variations in surface emissivities and lack of knowledge on the emissivity variation with viewing angle. To resolve this problem, a physics-based day/night algorithm ${ }^{20}$ was developed to retrieve surface spectral emissivity and temperature at $5 \mathrm{~km}$ resolution for the MODIS LST level-3 MOD11B1 product from a pair of daytime and nighttime MODIS data in seven TIR bands, i.e., bands 20,22, 23, 29, and 31-33. The accuracy of daily MODIS LST product has been validated in nineteen clear-sky cases with in-situ measurement data collected in field campaigns in 2000 and 2001. The MODIS LST accuracy is better than $1 \mathrm{~K}$ in the range from $263 \mathrm{~K}$ to $322 \mathrm{~K}$ over Lake Titicaca in Bolivia, Mono Lake, Bridgeport grassland, and a rice field in Chico, California, Walker Lake and a silt playa in Railroad Valley, Nevada, in the atmospheric column water vapor range from 0.4 to $3.0 \mathrm{~cm} .^{21}$ The MODIS LST product was also validated with in-situ TIR radiometer measurements in Lake Tahoe, CA/NV, in 27 clear-sky cases in 2000 and 2001 by Simon Hook, JPL, and it was found that the MODIS LST product has a small bias of $0.12 \mathrm{~K}$ and the standard deviation of its differences from the in-situ values is $0.3 \mathrm{~K}$ (personal communications). In mid July 2002, the MODIS LST product was also validated at the same accuracy with in-situ measurements in a soybean field near Greenville, Mississippi, in the atmospheric column water vapor range up to more than $4 \mathrm{~cm}$.

This paper presents the early results in monitoring thermal status of ecosystems with the MODIS LST and NDVI products.

\section{MODIS DATA PRODUCTS USED IN THIS STUDY}

Twelve sets of the 16-day MODIS VI product (MOD13A2) were ordered from the NASA EOS Data Gateway (http://redhook.gsfc.nasa.gov//imswww/pub/imswelcome/) in order to use the global NDVI data sets for year 2001. The file names and the starting dates of the periods of 16 days are listed in Table 1 . There are 281 files in each set of the VI product to cover all the land of the Earth between latitudes $60^{\circ} \mathrm{S}$ and $80^{\circ} \mathrm{N}$. The MODIS VI product provides NDVI data at the $1 \mathrm{~km}$-resolution grids in the integerized sinusoidal (ISIN) projection. The exact size of the $1 \mathrm{~km}$ grid is $0.928 \mathrm{~km}$ by $0.928 \mathrm{~km}$. The valid range of the NDVI data is from -2000 to 10000 , giving NDVI values in the range of -0.2 to 1.0 after divided by a scale factor of 10000 . We mosaiced all the files in each set and aggregated the NDVI data at $1 \mathrm{~km}$ grids into $5 \mathrm{~km}$ grids by taking average of all the NDVI data in the valid range. The NDVI values at $5 \mathrm{~km}$ grids in the mosaic images are stored in 8-bit unsigned integer in the valid range of 0 to 240 with the lower limit 0 corresponding to NDVI value -0.2 and the higher limit 240 corresponding to NDVI value of 1.0 . A quantization error of 0.0025 associated with the 8-bit unsigned integer is believed to be smaller than the error and uncertainty of the NDVI data. A fill value of 255 is given for grids in ocean and cloudy conditions. After this processing, we have 12 sets of global NDVI images representing monthly NDVI values in this study for the global except the polar regions.

For the whole year of 2001, the daytime and nighttime LSTs were taken from the daily $5 \mathrm{~km}$ MODIS LST product (MOD11B1) that is also available from the EOS Data Gateway free of charge. The LST data are stored in 16-bit unsigned integer in the valid range of 7500 to 65535 , giving LST values in the range of 150 to $1310.7 \mathrm{~K}$ after multiplying a scale factor of $0.02(\mathrm{~K})$. A fill value of 0 is given for grids in ocean and cloudy conditions. We mosaiced the LSTs in 317 tiles of the MOD11B1 product into global LST data set each day. Then the daily global LST sets were composited and averaged to obtain the monthly daytime and nighttime LST data sets for 2001 . The exact size of the $5 \mathrm{~km}$-resolution grids is $4.64 \mathrm{~km}$ by $4.64 \mathrm{~km}$. One set of global LST data at $5 \mathrm{~km}$ grids are stored in 4320 rows by 8640 columns. In the MODIS LST processing, only the MODIS data in clear-sky conditions at a confidence of $99 \%$ defined by the MODIS cloud-mask product (MOD35) are used to retrieve LST values. It is possible that there is no LST value for some grids that have valid NDVI values because a different definition of clear-sky pixels is used in the NDVI processing. A cirrus cloud may have an effect large enough to prevent LST retrieval at the $1 \mathrm{~K}$ accuracy, but it is not necessarily so for the NDVI estimation. The overpass time of the MODIS nadir observations is around 10:30am local solar time in the daytime and around 10:30pm local solar time at night. The MODIS observations at off-nadir viewing angles are made before or after the overpass time in term of the local solar time for the spots being observed. After the compositing and averaging in the generation of the monthly LST data, the daytime and nighttime LSTs represent the averaged LST values in clearsky conditions around 10:30am and 10:30pm local solar time, respectively. The MODIS LSTs represent the kinetic temperature determined by the TIR radiations from the surfaces of all components within the pixel or grid, including vegetation, soil, water body, and whatever being observed by the MODIS instrument. 


\section{NDVI PEAK ZONE APPROACH}

Because of the great diversity in the global ecosystems, the vegetation at the grids in a 16-day or monthly NDVI image may be in different stage of its phenology, some in growing phase and some in drying phase. In order to highlight the NDVI change at the global scale, a NDVI peak zone approach is applied in the following steps: (1) we separate the NDVI valid range into six sub-ranges, i.e., -0.2 to 0,0 to $0.2,0.2$ to $0.4,0.4$ to $0.6,0.6$ to 0.8 , and 0.8 to 1.0 ; (2) to find the maximum NDVI value in the 12 monthly NDVI images for each grid, assign it to one of the six sub-ranges according to its maximum NDVI value, and keep the month as its first index, after processing all grids, we get six images of NDVI peak zones as shown in Fig. 1, each corresponding to one of the six sub-ranges; (3) for all the grids in each NDVI peak zone, the NDVI values in 12 months are sorted in decreasing order and keep the corresponding months in the index images, resulting in 12 layers of NDVI images for each NDVI peak zone; (4) according to the index images, corresponding 12 layers of daytime and nighttime LST images are constructed for each NDVI peak zone. Fig. 1 shows the spatial distributions of the NDVI in the six NDVI peak zones. The images in (a) for the $0.8-1.0$ zone, (b) for the 0.6 to 0.8 zone, and (c) for the $0.4-0.6$ zone, were enhanced with the histogram equalization method for better visualization. As shown in Fig. 1 (a), NDVI peak values larger than 0.8 are distributed in tropical forests in South America and Africa and Far East, east part of the North America, northern parts of Europe and Asian, and the east part of Asian. These areas are neighboring by the $0.8-1.0$ NDVI peak zone shown in Fig. 1 (b). Semi-arid areas such the mid west of US and the interior of Australia are shown in Fig. 1 (c) and (d). Desert areas are shown in Fig. 1 (e) for the $0-0.2$ NDVI peak zone. The last zone ( -0.2 to 0$)$ is distributed mainly in Greenland.

\section{CHARACTERISTICS OF THE THERMAL STATUS OF THE ECOSYSTEMS}

From the 12 layers of NDVI and corresponding index images, daytime and nighttime LST images, we calculated the histograms of the NDVI, daytime LSTs and day-night LST differences for the five NDVI peak zones (covering NDVI from 0.0 to 1.0). Fig. 2 shows the histograms in layers 1,4 , and 7 . The histograms in layers 1,4 , and 7 are shown in columns 1,2, and 3, respectively. In layer 4 of the NDVI image, the time difference between the month with NDVI peak and the month with the 4 th largest NDVI value in 12 months may be 2-3 months, varying with grids. Similarly, the time difference in layer 7 of the NDVI image may be 3-6 months. Comparing the NDVI histograms in layers 1, 4 and 7 (from left to right in the top row) clearly shows the NDVI changes in the five NDVI peak zones. Comparing the histograms of daytime LSTs in the middle row shows that the daytime LSTs change toward low and high sides as the NDVI reduces. This feature in the histograms of daytime LSTs indicates that the growth of vegetation is limited at low LSTs due to cold weather and insufficient photosynthetically active radiation and at high LSTs due to strong evapotranspiration. From the histograms of the day-night LST differences in the bottom row, we can see that the daynight LST difference becomes slightly larger as the NDVI reduces. Because an increase in the day-night LST difference is related to a reduce in the apparent thermal inertia of the Earth surface in general and the apparent thermal inertia reduces as the soil gets dry ${ }^{22,23}$, the day-night LST difference may be used to estimate the soil moisture and monitor drought.

Means and standard deviations of the NDVI, daytime LSTs and day-night LST differences were also calculated. They are given in Table 2, and the number of $5 \mathrm{~km}$ grids with LSTs is given in the last column. The number of $5 \mathrm{~km}$ grids with LSTs may be different because there may be some grids without LST values due to persistent clouds in one month in some areas. When using the mean and standard deviation values in Table 2, beware that the shapes of the histograms in Fig. 2 are different from a normal distribution.

Analysis indicates that although there are weak correlations between NDVI and LST they are independent variables of the ecosystems at the global scale.

\section{POTENTIAL APPLICATIONS}

Now we try to apply MODIS LST and NDVI products in applications for monitoring thermal status of ecosystems, photosynthetic activity and drought. We have conducted field measurements with TIR radiometers in a grassland at $1972 \mathrm{~m}$ above sea level in Bridgeport, California since 2000. The size of the grasslands in the Bridgeport valley is about $5 \mathrm{~km}$ by $5 \mathrm{~km}$. The grasslands are irrigated during April 15 and September 15 in shadow canals with water originated from snow-melt in the Sierra Nevada just north of Mono Lake, approximately $30 \mathrm{~km}$ from the valley. This irrigated land is used for cattle grazing during the summer months. For a comparison, we also look at an unirrigated grassland at 
$1840 \mathrm{~m}$ above sea level near Ione, Nevada. This grassland is about $5 \mathrm{~km}$ wide and $15 \mathrm{~km}$ long on a gentle slope by the west edge of the Toiyabe National Forest, and approximately $160 \mathrm{~km}$ away from Bridgeport Valley.

Fig. 3 shows the NDVI, daytime LST and day-night LST difference values for the central portions of the flood-irrigated grassland in Bridgeport and the unirrigated grassland in Nevada in the spring and summer months of 2001. These values were taken from $1 \mathrm{~km}$ MODIS LST and NDVI products. From this figure, we can get the following insights: (1) In the Bridgeport site the dips in the daytime LSTs and the day-night LST differences are caused by irrigation. (2) The NDVI increases when the daytime LSTs are in the range up to $35^{\circ} \mathrm{C}$ in the spring and summer months. The NDVI in the irrigated grassland increases until the end of June. But the NDVI in the unirrigated grassland increases only in April and May. (3) The cooler daytime LSTs and smaller day-night LST differences in early July (julian day 188) in both sites indicate that there was a major storm event in the area at least from Bridgeport, CA to Ione, NV. This precipitation made a slight increase in the NDVI over the unirrigated grassland. The smaller day-night LST difference corresponds to the increase in the soil moisture condition in the unirrigated grassland. (4) The NDVI decreases as the daytime LST is above $35^{\circ} \mathrm{C}$. This example shows that MODIS LST and NDVI products can be used to monitor thermal status of the ecosystems, photosynthetic activity and drought.

The NDVI peak zone approach was also applied to latitude zones, for example, in the zone between latitudes 30-45 degree $\mathrm{N}$ that covers most of the USA, the Mediterranean region, Mid East, China, and Japan. We got similar NDVI and day-night LST difference histograms as shown in Fig. 2, but the daytime LST is distributed in smaller ranges and the standard deviations are also smaller. This NDVI peak zone approach can also be used in regions so that we can get the vegetation and thermal characteristics of the regional ecosystems.

When multi-year MODIS LST and NDVI products are available in the near future, we can get their annual variations in different ecosystems for better global and regional change studies.

\section{ACKNOLEDGMENT}

This work was supported by EOS Program contract NAS5-31370 and research grant NAG13-99023 of the National Aeronautics and Space Administration.

\section{REFERENCES}

1. V. Salomonson, W. Barnes, P. Maymon, H. Montgomery, and H. Ostrow, "MODIS: advanced facility instrument for studies of the Earth as a system,"' IEEE Trans. Geosci. Remote Sens., vol. 27, no. 2, pp. 145-153, 1989.

2. C. O. Justice, E. Vermote, J. R. G. Townshend, R. Defries, D. O. Roy, D. K. Hall, V. V. Salomonson, J. L. Privette, G. Riggs, A. Strahler, W. Lucht, R. B. Myneni, K. Knyazikhin, S.W. Running, P. R. Nemani, Z.Wan, A. R. Huete, W. van Leeuwen, R. E. Wolfe, L. Giglio, J.-P. Muller, and Y. Knyazikhin, M. J. Barnsley, "The Moderate Resolution Imaging Spectroradiometer (MODIS): land remote sensing for global change research," IEEE Trans. Geosci. Remote Sensing, vol. 36, pp. 1228-1249, 1998.

3. W. J. D. van Leeuwen, A. R. Huete, and T. W. Laing, "MODIS vegetation index compositing approach: a prototype with AVHRR data," Remote Sens. Environ., vol. 69, pp. 264-280, 1999.

4. T. Miura, A. R. Huete, H. Yoshioka, and B. N. Holben, "An error and sensitivity analysis of atmospheric resistant vegetation indices derived from dark target-based atmospheric correction," Remote Sens. Environ., vol. 78, pp. 284298, 2001.

5. J. T. Townshend, C. Justice, W. Li, C. Gurney, and J. McManus, "Global land cover classification by remote sensing: present capabilities and future possibilities,' Remote Sens. Environ., vol. 35, pp. 243-255, 1991.

6. G. Asrar, M. Fuchs, E. T. Kanemasu, and J. L. Hatfield, "Estimating absorbed photosynthetic active radiation and leaf area index from spectral reflectance in wheat," Agron. J., vol. 76, pp. 300-306, 1984.

7. C. Justice, J. R. G. Townshend, B. N. Holben, and C. J. Tucker, "Analysis of the phenology of global vegetation using meteorological satellite data," Int. J. Remote Sens., vol. 6, pp. 1271-1318, 1985.

8. P. C. Sellers, "Canopy reflectance, photosynthesis and transpiration,"' Int. J. Remote Sens., vol. 6, pp. 1335-1372, 1985. 
9. H. Mannstein, "Surface energy budget, surface temperature and thermal inertia," in Remote Sensing Applications in Meteorology and Climatology, ed. R. A. Vaughan and D. Reidel, NATO ASI Ser. C: Math. Phys. Sci. Vol. 201, pp. 391-410, Dordrecht, Netherlands: A Reidel Publishing Co., 1987.

10. P. J. Sellers, F. G. Hall, G. Asrar, D. E. Strebel, and R. E. Murphy, "The first ISLSCP Field Experiment (FIFE)," Bull. Amer. Meteorol. Soc., vol. 69, no. 1, pp. 22-27, 1988.

11. D. Ehrlich and E. F. Lambin, "The surface temperature-vegetation index space for land cover and land-cover change analysis," Int. J. Remote Sens., vol. 17, no. 3, pp. 463-487, 1996.

12. E. F. Lambin and D. Ehrlich, "Land-cover changes in sub-Saharan Africa (1982-1991): Application of a change index based on remotely sensed surface temperature and vegetation indices at a continental scale," Remote Sens. Environ., vol. 61, no. 2, pp. 181-200, 1997.

13. C. M. Feldhake, D. M. Glenn, and D. L. Peterson, "Pasture soil surface temperature response to drought," Agron. J., vol. 88, no. 4, pp. 652-656, 1996.

14. T. R. McVicar and D. L. B. Jupp, "The current and potential operational uses of remote sensing to aid decisions on drought exceptional circumstances in Australia: a review,' Agricultural Systems, vol. 57, no. 3, pp. 399-468, 1998.

15. R. D. Jackson, R. J. Reginato, and S. B. Idso, "Wheat canopy temperature: a practical tool for evaluating water requirements," Water Resour. Res., vol. 13, pp. 651-656, 1977.

16. V. Caselles and J. A. Sobrino, "Determination of frosts in orange groves from NOAA-9 AVHRR data," Remote Sens. Environ., vol. 29, no. 2, pp. 135-146, 1989.

17. Z. Wan and J. Dozier, "A generalized split-window algorithm for retrieving land-surface temperature from space," IEEE Trans. Geosci. Remote Sens., vol. 34, no. 4, pp. 892-905, 1996.

18. W. C. Snyder, Z. Wan, Y. Zhang, and Y.-Z. Feng, "Classification-based emissivity for land surface temperature measurement from space," Int. J. Remote Sens., vol. 19, no. 14, pp. 2753-2774, 1998.

19. W. Snyder and Z. Wan, "BRDF models to predict spectral reflectance and emissivity in the thermal infrared," IEEE Trans. Geosci. Remote Sens., vol. 36, no. 1, pp. 214-225, 1998.

20. Z. Wan and Z.-L. Li, "A physics-based algorithm for retrieving land-surface emissivity and temperature from EOS/MODIS data," IEEE Trans. Geosci. Remote Sens., vol. 35, no. 4, pp. 980-996, 1997.

21. Z. Wan, Y. Zhang, Q. Zhang, and Z.-L. Li, "Validation of the land-surface temperature products retrieved from Terra Moderate Resolution Imaging Spectroradiometer data,' Remote Sens. Environ., in press 2002.

22. J. C. Price, "On the analysis of thermal infrared imagery: the limited utility of apparent thermal inertia," Remote Sens. Environ., vol. 18, pp. 59-73, 1985.

23. A. B. Kahle, "Surface emittance, temperature, and thermal inertia derived from Thermal Infrared Multispectral Scanner (TIMS) data for Death Valley, California,"' Geophysics, vol. 52, no. 7, pp. 858-874, 1986. 
TABLE I. A list of the 16-day NDVI data sets used in this study.

\begin{tabular}{cllc}
\hline \multicolumn{1}{c}{ file name } & starting date & \multicolumn{1}{c}{ file name } & starting date \\
\hline MOD13A2.A2001001*.003.*.hdf & $01 / 01 / 2001$ & MOD13A2.A2001193*.003.*.hdf & $07 / 12 / 2001$ \\
MOD13A2.A2001033*.003.*.hdf & $02 / 02 / 2001$ & MOD13A2.A2001225*.003.*.hdf & $08 / 13 / 2001$ \\
MOD13A2.A2001065*.003.*.hdf & $03 / 06 / 2001$ & MOD13A2.A2001257*.003.*.hdf & $09 / 14 / 2001$ \\
MOD13A2.A2001097*.003.*.hdf & $04 / 07 / 2001$ & MOD13A2.A2001273*.003.*.hdf & $09 / 30 / 2001$ \\
MOD13A2.A2001129*.003.*.hdf & $05 / 09 / 2001$ & MOD13A2.A2001305*.003.*.hdf & $11 / 01 / 2001$ \\
MOD13A2.A2001145*.003.*.hdf & $05 / 29 / 2001$ & MOD13A2.A2001337*.003.*.hdf & $12 / 03 / 2001$ \\
\hline
\end{tabular}

Fig. 1 Spatial distributions of the NDVI in the six NDVI peak zones.

Note that the images in (a) - (c) were enhanced with the histogram equalization method.

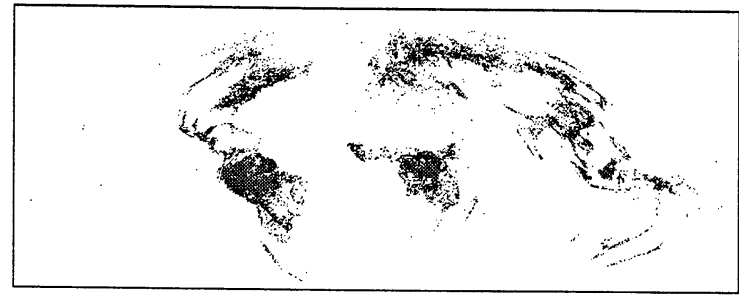

(a) $0.8-1.0$

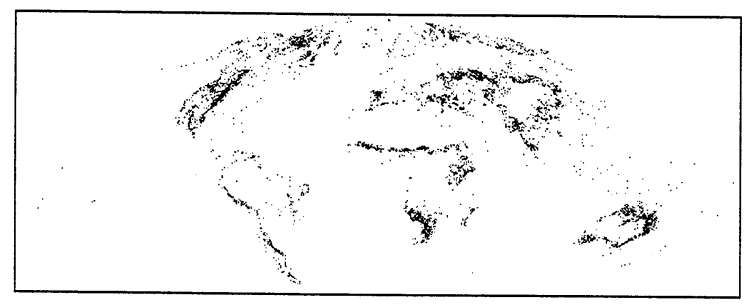

(c) $0.4-0.6$

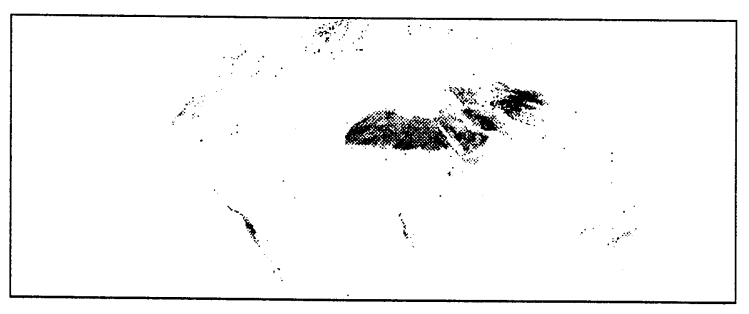

(e) $0.0-0.2$

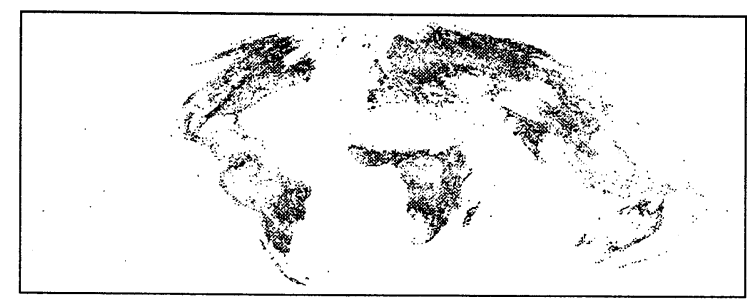

(b) $0.6-0.8$

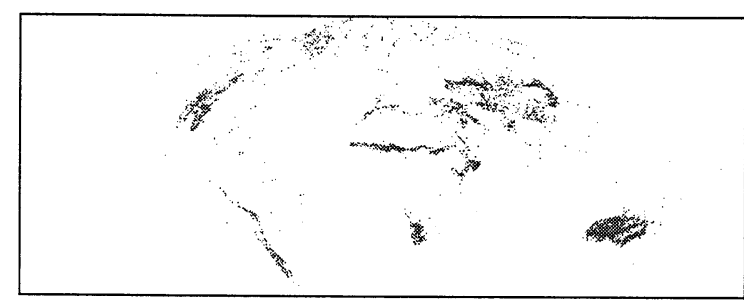

(d) $0.2-0.4$

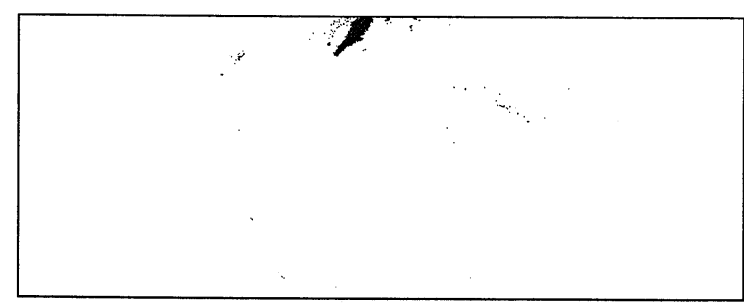

(f) $-0.2-0.0$ 
Fig. 2, Histograms of the NDVI (a), daytime LST (b), and day-night LST difference (c) in layers 1, 4, and 7 of NDVI images.

\# of $5 \mathrm{~km}$ grids

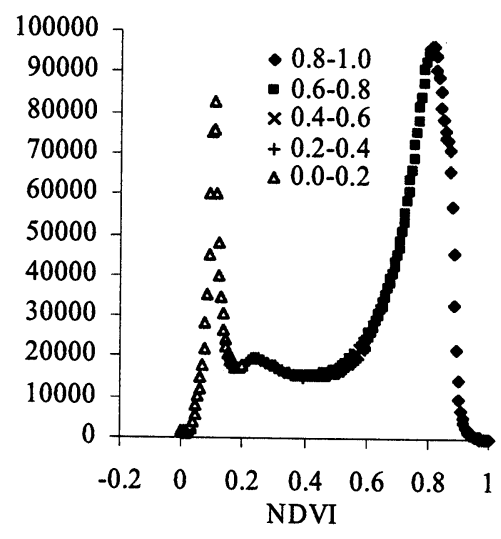

\# of $5 \mathrm{~km}$ grids

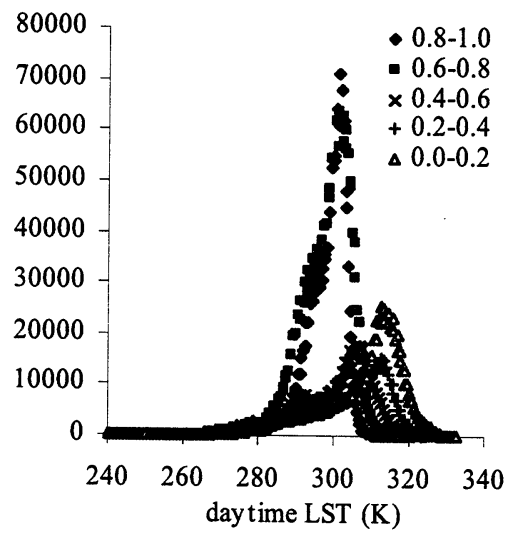

\# of $5 \mathrm{~km}$ grids

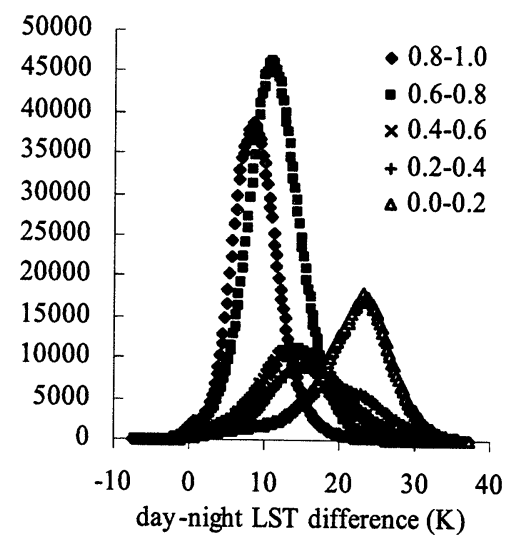

(a)

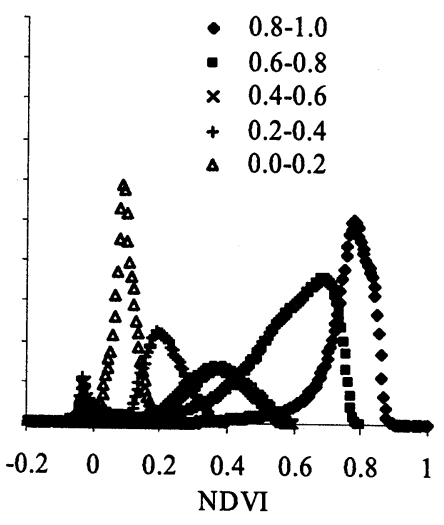

(b)
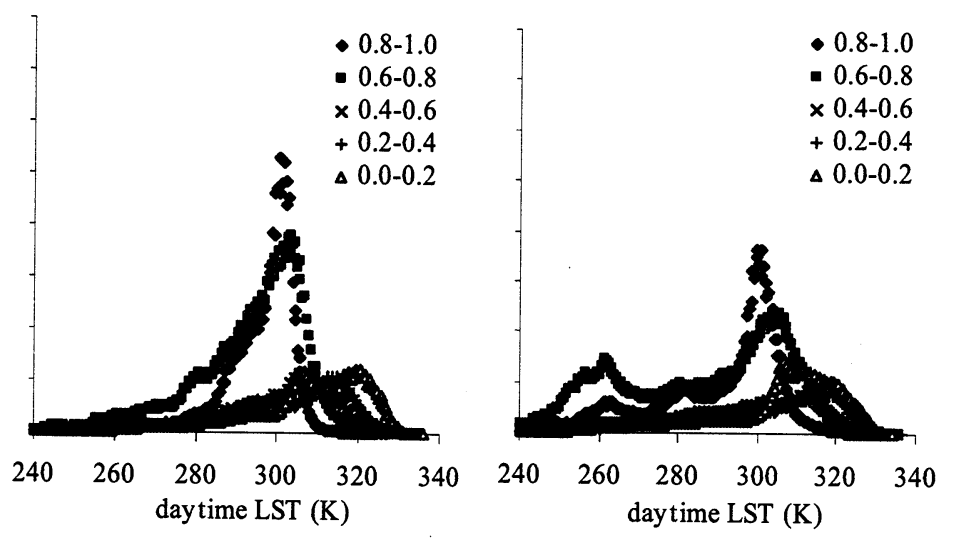

(c)

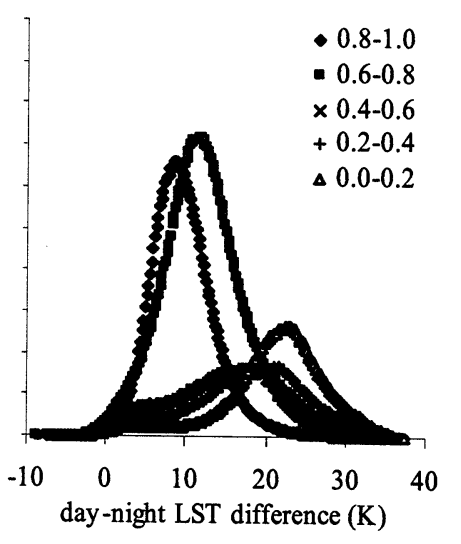

- $0.8-1.0$

- $0.6-0.8$

$\times 0.4-0.6$

$+0.2-0.4$

$\triangle 0.0-0.2$

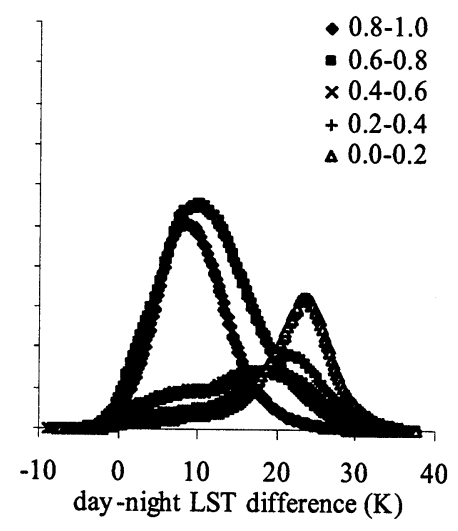


TABLE II. Mean and standard deviation ( ) values of NDVI, daytime LSTs and day-night LSTs in five NDVI peak zones.

\begin{tabular}{|c|c|c|c|c|c|c|c|}
\hline \multirow[b]{2}{*}{ Layer } & \multicolumn{2}{|c|}{ NDVI } & \multicolumn{2}{|c|}{ daytime LST } & \multicolumn{2}{|c|}{ day-night LST difference } & \multirow{2}{*}{$\begin{array}{c}\text { number of grids } \\
\text { with } \\
\text { LSTs } \\
\end{array}$} \\
\hline & mean & ( ) & $\begin{array}{c}\text { mean } \\
\left({ }^{\circ} \mathrm{C}\right) \\
\end{array}$ & $\begin{array}{c}(\text { ) } \\
\left({ }^{\circ} \mathrm{C}\right) \\
\end{array}$ & $\begin{array}{c}\text { mean } \\
\left({ }^{\circ} \mathrm{C}\right)\end{array}$ & $\begin{array}{l}(\text { ) } \\
\left({ }^{\circ} \mathrm{C}\right) \\
\end{array}$ & \\
\hline & & & \multicolumn{4}{|c|}{ in the NDVI peak zone of 0.8 to 1.0} & \\
\hline 1 & 0.8429 & 0.0284 & 24.96 & 5.38 & 8.724 & 3.552 & 1476258 \\
\hline 2 & 0.8136 & 0.0451 & 24.79 & 5.53 & 8.879 & 3.599 & 1481741 \\
\hline 3 & 0.7833 & 0.0680 & 24.14 & 6.52 & 9.153 & 3.872 & 1472496 \\
\hline 4 & 0.7494 & 0.0951 & 23.24 & 7.92 & 9.370 & 4.096 & 1461050 \\
\hline 5 & 0.7069 & 0.1263 & 22.11 & 9.80 & 9.591 & 4.402 & 1447721 \\
\hline 6 & 0.6502 & 0.1654 & 20.16 & 12.16 & 9.499 & 4.578 & 1430770 \\
\hline 7 & 0.5790 & 0.2053 & 17.83 & 14.94 & 9.334 & 4.791 & 1415002 \\
\hline & & & \multicolumn{4}{|c|}{ in the NDVI peak zone of 0.6 to 0.8} & \\
\hline 1 & 0.7239 & 0.0553 & 25.08 & 6.47 & 11.213 & 3.928 & 2026743 \\
\hline 2 & 0.6833 & 0.0753 & 24.83 & 7.10 & 11.561 & 4.106 & 2037299 \\
\hline 3 & 0.6256 & 0.1181 & 23.18 & 9.70 & 11.911 & 4.652 & 2023836 \\
\hline 4 & 0.5580 & 0.1700 & 20.76 & 13.06 & 11.867 & 5.025 & 2020403 \\
\hline 5 & 0.4891 & 0.2064 & 18.61 & 15.73 & 11.817 & 5.353 & 2023629 \\
\hline 6 & 0.4196 & 0.2281 & 16.10 & 17.99 & 11.498 & 5.529 & 2024372 \\
\hline \multirow[t]{2}{*}{7} & 0.3489 & 0.2363 & 13.40 & 20.56 & 11.185 & 5.940 & 2028772 \\
\hline & & & \multicolumn{3}{|c|}{ in the NDVI peak zone of 0.4 to 0.6} & & \\
\hline 1 & 0.5075 & 0.0586 & 27.42 & 9.10 & 14.247 & 5.552 & 708130 \\
\hline 2 & 0.4570 & 0.0765 & 27.78 & 9.50 & 14.807 & 5.712 & 711114 \\
\hline 3 & 0.3914 & 0.1116 & 26.11 & 13.05 & 15.084 & 6.236 & 712398 \\
\hline 4 & 0.3249 & 0.1450 & 23.39 & 17.52 & 14.887 & 6.937 & 709320 \\
\hline 5 & 0.2804 & 0.1535 & 22.24 & 18.73 & 15.106 & 7.149 & 707539 \\
\hline 6 & 0.2495 & 0.1530 & 21.04 & 19.42 & 14.997 & 7.183 & 702404 \\
\hline \multirow[t]{2}{*}{7} & 0.2268 & 0.1524 & 20.01 & 20.27 & 14.883 & 7.436 & 702083 \\
\hline & & & \multicolumn{3}{|c|}{ in the NDVI peak zone of 0.2 to 0.4} & & \\
\hline 1 & 0.2955 & 0.0572 & 30.22 & 10.62 & 16.826 & 6.294 & 698779 \\
\hline 2 & 0.2624 & 0.0620 & 30.54 & 11.21 & 17.287 & 6.346 & 698010 \\
\hline 3 & 0.2260 & 0.0764 & 29.25 & 14.45 & 17.519 & 6.749 & 696510 \\
\hline 4 & 0.1958 & 0.0857 & 27.66 & 17.56 & 17.671 & 7.212 & 695923 \\
\hline 5 & 0.1775 & 0.0874 & 27.56 & 18.26 & 18.076 & 7.259 & 694568 \\
\hline 6 & 0.1644 & 0.0869 & 27.81 & 18.55 & 18.352 & 7.296 & 688912 \\
\hline \multirow[t]{2}{*}{7} & 0.1530 & 0.0878 & 27.37 & 19.42 & 18.279 & 7.378 & 677752 \\
\hline & & & \multicolumn{3}{|c|}{ in the NDVI peak zone of 0.0 to 0.2} & & \\
\hline 1 & 0.1149 & 0.0372 & 33.64 & 12.36 & 20.913 & 6.008 & 983021 \\
\hline 2 & 0.1033 & 0.0376 & 32.45 & 12.84 & 21.294 & 6.058 & 963079 \\
\hline 3 & 0.0941 & 0.0393 & 32.92 & 14.75 & 21.391 & 6.255 & 936850 \\
\hline 4 & 0.0868 & 0.0427 & 32.92 & 17.08 & 20.876 & 6.546 & 829195 \\
\hline 5 & 0.0821 & 0.0464 & 32.90 & 18.10 & 20.900 & 6.736 & 758033 \\
\hline 6 & 0.0823 & 0.0461 & 32.94 & 17.26 & 21.131 & 6.500 & 830555 \\
\hline 7 & 0.0817 & 0.0445 & 32.18 & 16.70 & 21.009 & 6.342 & 854213 \\
\hline
\end{tabular}


Fig. 3, Comparisons of NDVI (a), daytime LST and day-night LST difference in an irrigated grassland in Bridgeport (b) and a non-irrigated grassland in NV (c) in 2001.

(a)

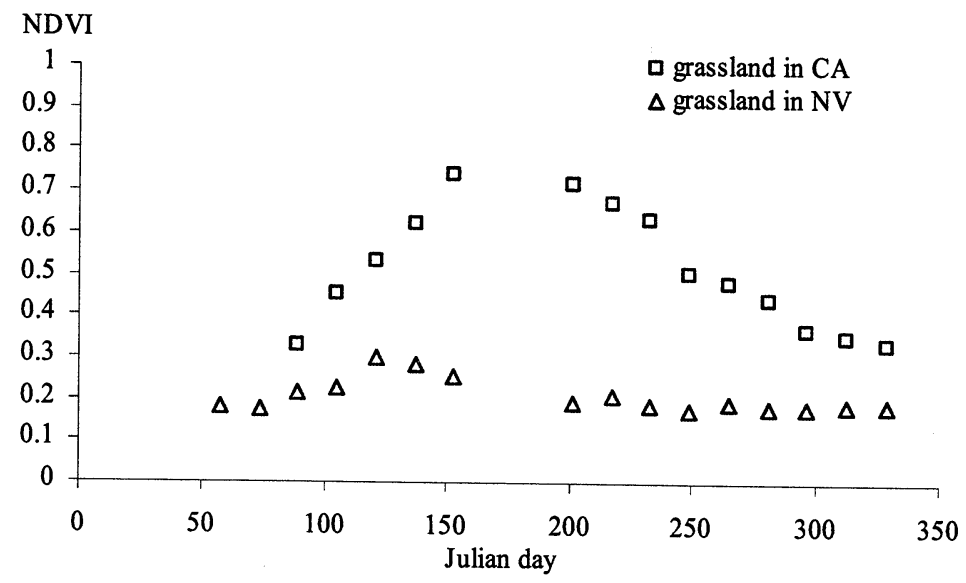

(b)

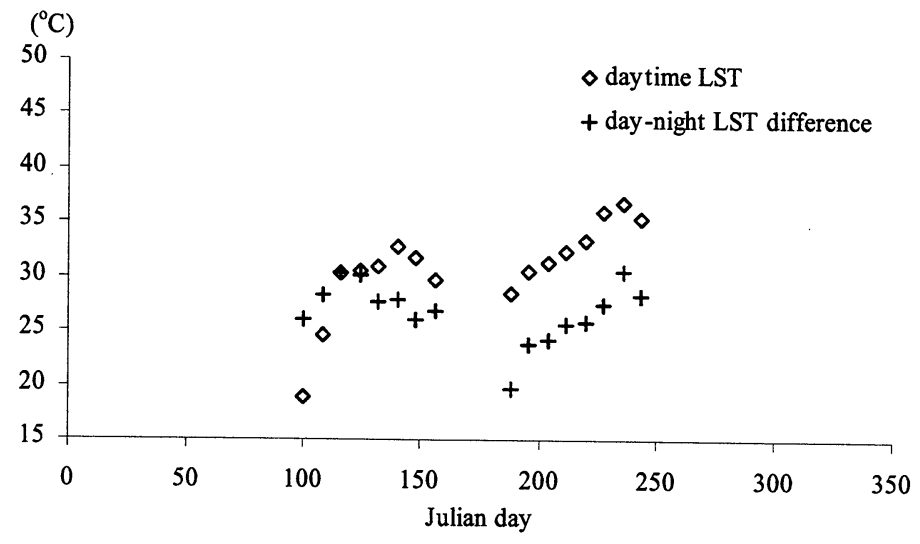

(c)

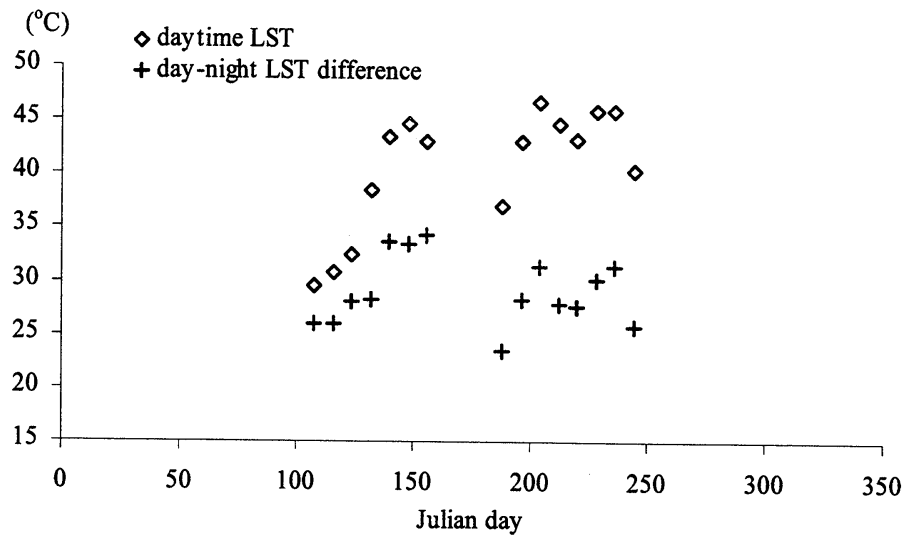

